\title{
CALCULATION OF BOIL-OFF GAS (BOG) GENERATION OF KC-1 MEMBRANE LNG TANK WITH HIGH DENSITY RIGID POLYURETHANE FOAM BY NUMERICAL ANALYSIS
}

\author{
Hyeonwon Jeong \\ W. Jaewoo Shim \\ Department of Chemical Engineering, Dankook University, Yongin-si, Gyeonggi-do 16890, Korea
}

\begin{abstract}
Recently, a new type of LNG tank named "KC-1 membrane LNG tank" has been developed by Korean Gas Corporation (KOGAS), and Samsung Heavy Industries (SHI) is currently building KC-1 membrane type LNG carriers. Unlike other LNG tanks, the KC-1 membrane LNG tank has a single-insulation structure rather than a double-insulation structure. For a given tank's boundary condition, heat transfer analysis is performed from the external to the internal environment of the LNG tank by numerical simulation for three tanks. In each tank, the main thermally resistant layer of insulation is assembled with a High density rigid Polyurethane Foam (H-PUF), which is blown with one of three different types of hydrofluorocarbons-namely-HFC-365mfc, 245fa, and 245fa-e (enhanced). Advantage of such blowing agents is that it has a lower Ozone Depletion Potential (ODP) than HCFC-141b or carbon dioxide $\left(\mathrm{CO}_{2}\right)$ that has been used in the past as well as having low thermal conductivity. A Reduced Order Model is utilized to a 3-dimensional section of the insulation to calculate equivalent thermal conductivity. The equivalent thermal conductivity of the insulation is then applied to the rest of LNG tank, reducing the size of tank simulation domain as well as computation time. Tank's two external and internal boundary conditions used are those defined by the International Code for the Construction and Equipment of Ships Carrying Liquefied Gases in Bulk (IGC) and the United States Coast Guard (USCG) conditions. Boil-off Rate (BOR) of the tank that has the insulation with H-PUF blown with HFC-245fa resulted in 0.0927 \%/day and $0.0745 \% /$ day for IGC and USCG conditions, respectively..
\end{abstract}

Keywords: boil-off gas, KC-1 membrane, LNG carrier, rigid polyurethane foam, ozone depletion potential

\section{INTRODUCTION}

Following the 1973 oil crisis, Natural Gas (NG) has received the spotlight as an alternative fuel source to oil. To facilitate efficient transport, it is preferably liquefied into Liquefied Natural Gas (LNG) and transported in a carrier via sea from the origin to the destination rather than by land pipelines that transports in compressed gaseous state. This method of transportation is highly efficient and widely used not only because the same NG mass that is liquefied at around $-163^{\circ} \mathrm{C}$ would occupy only $1 / 614$ the volume but the versatility of route coverage of ever growing destinations throughout the world. With international trade of LNG in 2015 reaching an estimated 244.8 million tons (MT), which is a $4.7 \mathrm{MT}$ increase from 2014 and surpassing the previous high of 241.5 MT in
2011, it is clear that LNG has become an important energy source to mankind $[1,2]$.

While LNG is stored in tanks that have excellent insulating properties to maintain its liquid state, if heat transfer from the exterior becomes excessive, evaporation can be a problem as it would increase the tank pressure compromising the safety of the tank. As a preventive measure, most LNG tanks are designed with a safety valve that can alleviate the pressure of the tank by releasing excess Boil-off Gas (BOG) into the atmosphere when required. However, continued release of BOG to air can cause a loss of LNG quality, which is also known as ageing or weathering. This happens because the relatively lighter components, nitrogen and methane, evaporate first, thereby decreasing the energy content of the 
LNG left in the tank. If ageing or weathering is excessive, not only does LNG lose its value as an energy source, but there is also the potential danger of air pollution that exacerbate the greenhouse effect through the released gas [3-7].

As a response to these issues, the International Maritime Organization (IMO) has set a regulation on how much BOG a LNG tank is permitted under a given tank condition, indirectly overseeing the insulation performance of LNG tanks. The current IMO regulation with LNG tank design and operation has set a limit of Boil-Off Rate (BOR) at 0.15 \%/day (\% evaporated LNG mass/loaded LNG mass day). Following the 2015 Paris Agreement, as the regulations on the release of greenhouse gases during maritime transport become stricter, the efforts to avoid excessive BOG generation utilizing techniques such as re-liquefaction of generated gases or reusing the gases as ship's fuel are on the rise. Therefore, the accurate prediction of BOG generation is becoming more important to LNG tank designs that can meet future IMO standard [8]. Previous investigations of BOG generation focused primarily on the evaporation of cryogens in smallscale laboratory experiments in a cryostat. Experiments that take into account of the actual size and structural complexity of LNG tanks are quite limited. For example, experiments done in cryostats to investigate LNG evaporation rate are mostly evaporation rate studies of liquefied nitrogen in small rectangular containers. Very few of these studies meet the high Rayleigh number $\left(\mathrm{Ra}>10^{9}\right)$ condition that is seen in actual LNG tanks under natural convection conditions [9]. Although these experimental results are important as they are fundamentals of cryogenic liquid evaporation, but they have limited applications toward the design of an actual complex structure of LNG tank.

Samsung Heavy Industries (SHI) is currently developing a LNG carrier that can load the KC-1 membrane LNG tanks that has been developed by the Korea Gas Corporation (KOGAS) with their proprietary technology. For the performance test of KC-1 insulation, the experiment was conducted on a $250 \mathrm{~m}^{3}$ sized closed LNG mock-up tank containing a $135^{\circ}$ corner panel. This experiment was performed mostly to confirm some of important theoretical design criteria and the existence of a limitation in extending the results of estimating BOG in a LNG tank of actual size [10]. As a result of the lack of experiments, most investigations involving predictions of BOG generation in LNG tanks are done indirectly through numerical simulation. It is necessary to carry out more simulation studies that can accurately predicts BOG generation levels in LNG tanks under more realistic shipping environmental conditions for the oceanic LNG transportation.

Currently, Polyurethane Foam (PUF) is commonly used as a layer of an insulator in the interior of the LNG tanks as well as insulators in various industrial equipment. PUF consists of polymer skeleton with its cells filled with blowing agents of 1,1-dichloro-1-fluoroethane (HCFC-141b) or carbon dioxide $\left(\mathrm{CO}_{2}\right)$ during the manufacturing process of PUF. However, since refrigerants such as HCFC-141b has a high Ozone Depletion Potential (ODP), there are renewed efforts to develop a more environment friendly blowing agent [11]. In recent years, hydrofluorocarbons (HFC) have been replacing HCFC-141b as an alternative, environmentfriendly refrigerant [12]. In responding to the recent increased environmental regulation, this study aims to apply High Density Rigid PUF (H-PUF) with a HFC blowing agent in the insulation of KC-1 LNG tank and quantitatively assess the temperature distribution in the tank structure to predict BOG generation levels in the tank.

In the thermal analysis of the actual LNG tank, a commercial code, FLUENT, is used for the numerical simulation. To shorten the computation time, Reduced Order Models (ROM) is applied to the insulation thereby reducing the number of structural grids required to simulate the insulation. ROM allows the layers of insulation to be simplified into a single material layer such that an equivalent thermal conductivity $\left(\mathrm{k}_{\mathrm{eq}}\right)$ can be calculated for the insulation and the inner hull as a whole. The calculated $\mathrm{k}_{\mathrm{eq}}$ is then applied to the rest of the inner hull and the insulation of the tank, reducing the computation domain of the tank structure. Moreover, since the tank is symmetric as viewed from the mid-lines along the longitudes and latitude of the tank, the numerical domain of the tank is further reduced to the $1 / 4$ of the tank. Thus, $1 / 4$ of the tank structure is discretized to form numerical grids for the numerical simulation corresponding to boundary conditions that are defined by the International Code for the Construction and Equipment of Ships Carrying Liquefied Gases in Bulk (IGC) and the United States Coast Guard Code (USCG). In each case, it is assumed that LNG and NG remained at a constant internal tank temperature of $-163^{\circ} \mathrm{C}$ and $-158^{\circ} \mathrm{C}$, respectively, and that LNG occupy $98 \%$ and NG occupy $2 \%$ of the tank volume. The results of other researchers are compared with results from this study to validate the methodology used in this study as well as examining the $\mathrm{H}$-PUF insulation performance on the overall insulation of KC-1 membrane LNG tank.

\section{PROBLEM DEFINITION}

\section{DESCRIPTION OF KC-1 MEMBRANE LNG TANK}

The problem definition involves the heat transfer from the maritime external environment to the LNG stored in the tanks of a LNG carrier. The sailing condition of the carrier is assumed to be at $19.5 \mathrm{knot}$ and that the external thermal boundary condition of the tank is as defined in IGC (air: $45^{\circ} \mathrm{C}$, seawater: $32^{\circ} \mathrm{C}$ ) and USCG (air: $-18^{\circ} \mathrm{C}$, seawater: $0^{\circ} \mathrm{C}$ ) for the thermal analysis. Fig. 1 shows a LNG carrier that has a capacity of 174,000 $\mathrm{m}^{3}$ with the four-LNG tank arrangement. The KC-1 LNG carrier has a maximum hull length of $296 \mathrm{~m}$ and scantling draught of $13.0 \mathrm{~m}$. Since the thermal analysis of four LNG tanks mounted on a KC-1 LNG carrier requires a considerable amount of CPU time as well as the difficulties that may arise in the numerical convergence which encompass all the details, the simulation is simplified to perform only on 
the actual structure of the no.3 LNG tank and the adjoining cofferdam. Since the 1/4 tank, shown in red dotted box of Fig. 1, is geometrically symmetrical about the mid-line in the longitudinal direction as well as about the mid-line in the lateral direction of the carrier, the numerical domain can be further reduced to the $1 / 4$ of no. 3 tank. It is assumed that both the external and internal temperature conditions of the tank are also symmetric as the thermal boundary conditions of the cofferdams between tanks are also assumed to be the same. Thus the numerical simulation problem can be simplified to the structure consisting of only the $1 / 4$ of the actual no. 3 LNG tank and the $1 / 2$ of the adjacent cofferdam to describe the thermal behavior in the $1 / 4$ of LNG tank.

Fig. 2 shows the dimensions of the no. 3 LNG tank that has volume of $48,280 \mathrm{~m}^{3}$. The LNG tank has the dimension of $45.6 \mathrm{~m}$ by $46.05 \mathrm{~m}$, in lateral and longitudial direction, respectively, and $34.99 \mathrm{~m}$ in height. The LNG tank is assumed to be filled to $98 \%$ of the capacity. The KC-1 LNG tank is designed with an outer and inner hull to meet the double hull structure requirement of the IMO regulations and it is constructed with steel of thickness of 15-20 mm [13]. Ballast compartment (BC), which is located between the outer and inner hull, is designed to maintain the space that can be filled with ballast water and sustain the structural shape of the hull. The octagonal pillar structure of the LNG tank is constructed using $90^{\circ}$ and $135^{\circ}$ corner panels, and the connecting joint part of the trihedral panels are used join the cofferdam compartment and BC. The thickness of steel used for the outer and inner hull that surrounds BC is assumed to be $20 \mathrm{~mm}$, and the space of $\mathrm{BC}$ and cofferdam compartment are assumed to be filled with air.

A schematic view of cross-section of KC-1 LNG tank's wall structure comprising of outer and inner hauls, BC and insulation is shown in Fig. 3. Unlike the double insulation structures of Mark-III and GT96, KC-1 insulation is composed of a single insulation structure that includes a high density rigid polyurethane foam (H-PUF) layer with a blowing agent in its cells $[14,15]$. The purpose of such design is to simplify geometry of the insulation structure to facilitate easier construction and maintenance while meeting the insulation performance of a double insulation structure [16]. To account for the thermal expansion and contraction phenomenon of LNG, a double-stainless steel-membrane layer, composed of primary and secondary membrane layers, constitutes the inner surface of the tank. This double membrane layer is to support structural integrity and to enhance safety in the event leakage of LNG through the primary membrane layer occurs.

Fig. 3 also shows details of the insulation that consists of six layers: primary and secondary membrane layers, H-PUF, mastic and air, and top and bottom plywood. There is a mastic/ air layer with a thickness of $10 \mathrm{~mm}$ between the inner hull and the bottom plywood layer of the insulation, and a top and a bottom plywood layers on the sides of the H-PUF, each having the thickness of $12 \mathrm{~mm}$. The primary and secondary membrane layers are both constructed with stainless steel with a thickness of $1.5 \mathrm{~mm}$, and the primary membrane layer is in direct contact with the LNG. The space between the membrane layers is filled with plywood, nuts, and volts, however, the space from the primary membrane layer to the secondary membrane layer is assumed to be filled with steel such that the double membrane layers is reduced to a single stainless steel (SUS304) membrane layer with a thickness of $13.5 \mathrm{~mm}$. The outer and inner hulls supporting the structure of the KC-1 insulation are of $9 \%$ nickel steel $[17,18]$.

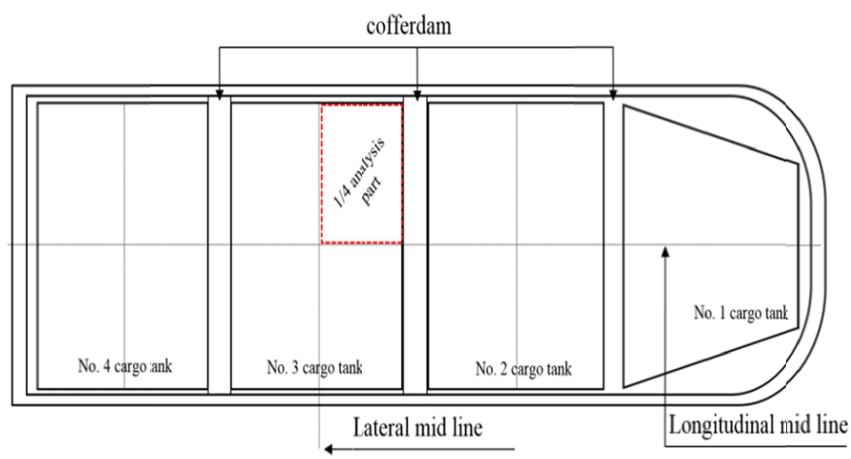

Fig. 1. Tank arrangements of KC-1 LNG carrier

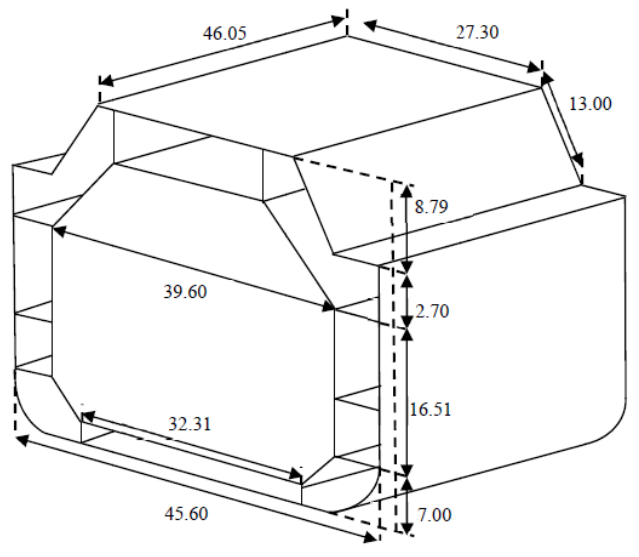

Fig. 2. Dimensions of KC-1 LNG tank (size in $\mathrm{m}$ )

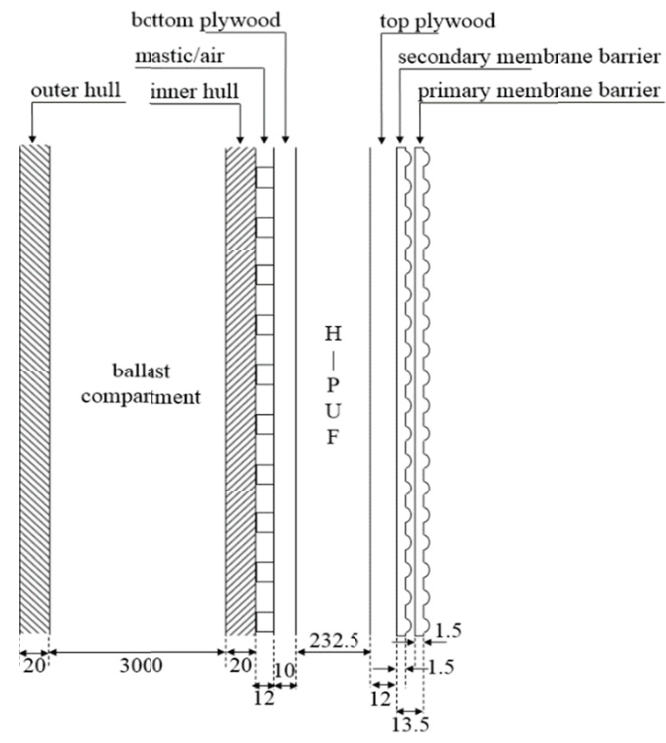

Fig. 3. Cross-sectional dimension of KC-1 LNG tank's wall structure (size in $\mathrm{mm})$ 


\section{PROPERTIES OF KC-1 INSULATION MATERIALS}

The mastic/air layer, also shown in Fig. 3, is constructed as a layer to support for the gap between the plywood and the inner hull. Mastic of mastic/air layer is assumed to be of fiberglass/G10 epoxy, and the mastic/air layer is assumed to be a unified layer of a single material that has a composition of 1:3 volume averaged ratio of the epoxy and air [16]. The thermal conductivities of the unified mastic/air layer along with the other insulation materials as a function of temperature is shown in Table $1[19,20]$. Table 2 shows the thermal conductivities of H-PUF with three different blowing agents [14]. In most of the previous thermal analysis of LNG tanks, the thermal conductivity of insulation materials is assumed to have a constant value [19-27]. However, in efforts to simulate the LNG tank under more realistic shipping environmental conditions, the linearly interpolated thermal conductivity as a function of temperature is applied in the numerical calculations.

Table 1. Thermal conductivities of KC-1 insulation and hull materials $\left[\boldsymbol{W} / \boldsymbol{m} \cdot{ }^{\circ} \mathrm{C}\right]$

\begin{tabular}{|c|c|c|c|c|}
\hline temperature $\left[{ }^{\circ} \mathrm{C}\right]$ & $\begin{array}{c}\text { membrane } \\
\text { layer }\end{array}$ & $\begin{array}{c}\text { top/bottom } \\
\text { plywood }\end{array}$ & mastic/air & hull (steel) \\
\hline-163 & 9.6916 & 0.062 & 0.1808 & 17.0059 \\
\hline-133 & 10.8395 & 0.074 & 0.2082 & 20.0810 \\
\hline-72 & 12.6644 & 0.095 & 0.2662 & 24.5266 \\
\hline-30 & 13.7986 & 0.108 & 0.3082 & 26.4336 \\
\hline 10 & 14.8623 & 0.118 & 0.3494 & 27.5403 \\
\hline 20 & 15.1273 & - & 0.3598 & 27.7222 \\
\hline
\end{tabular}

The H-PUF layer of KC-1 insulation is composed of polymeric skeletons with its cells filled with a blowing agent. Commonly, Trichlorofluoromethane (CFC-11), 1, 1-dichloro1-fluoroethane (HCFC-141b) or carbon dioxide $\left(\mathrm{CO}_{2}\right)$ have been used as the blowing agents in the past, but in recent years, hydrofluorocarbons (HFCs) have been sought as the alternative the blowing agents due to relative low Ozone Depletion Potential (ODP). The three HFC blowing agents considered in this study are: 1,1,1,3,3-pentafluorobutane (HFC-365mfc), 1,1,1,3,3-pentafluoropropane (HFC-245fa) and HFC-245fa enhanced (HFC-245fa-e). HFC-245fa-e is essentially an enhanced HFC-245fa blowing agent that has improved mixing efficiency due to added mobile liquid called Perfloroalkane (PFA). The thermal analysis is focused particularly on the insulation performance of H-PUF layer, each with one the three blowing agents, as the layer has the largest temperature drop amongst all the layers in the insulation $[12,14]$.

Physical properties of air and seawater are shown in Table 3 and 4, respectively, and the values are linear interpolated as a function of temperature to calculate heat transfer coefficients $[21,27]$. The physical properties of the seawater shown in Table 4 are at $35 \mathrm{~g} / \mathrm{kg}$, which is the average salinity of the North Atlantic Ocean [28].
Table 2. Thermal conductivities of H-PUF with 3 different blowing agents

\begin{tabular}{|c|c|c|c|}
\hline $\begin{array}{l}\text { temperature } \\
{\left[{ }^{\circ} \mathrm{C}\right]}\end{array}$ & $\begin{array}{l}\mathrm{k}_{\mathrm{H}-\mathrm{PUF}} \text { of } \\
\text { HFC-365mfc } \\
{\left[\mathrm{W} / \mathrm{m} \cdot{ }^{\circ} \mathrm{C}\right]}\end{array}$ & $\begin{array}{l}\mathrm{k}_{\mathrm{H}-\mathrm{PUF}} \text { of } \\
\mathrm{HFC}-245 \mathrm{fa} \\
{\left[\mathrm{W} / \mathrm{m} \cdot{ }^{\circ} \mathrm{C}\right]}\end{array}$ & $\begin{array}{l}\mathrm{k}_{\mathrm{H}-\mathrm{PUF}} \text { of } \\
\text { HFC-245fa-e } \\
{\left[\mathrm{W} / \mathrm{m} \cdot{ }^{\circ} \mathrm{C}\right]}\end{array}$ \\
\hline-160 & 0.01535 & 0.01517 & 0.01474 \\
\hline-120 & 0.01677 & 0.01679 & 0.01631 \\
\hline-80 & 0.01923 & 0.01846 & 0.01852 \\
\hline-40 & 0.02051 & 0.01917 & 0.01909 \\
\hline-20 & 0.02097 & 0.01986 & 0.01987 \\
\hline 20 & 0.02412 & 0.02330 & 0.02280 \\
\hline
\end{tabular}

Table 3. Physical properties of air [27]

\begin{tabular}{|c|c|c|c|}
\hline $\begin{array}{c}\text { temperature } \\
{\left[{ }^{\circ} \mathrm{C}\right]}\end{array}$ & $\begin{array}{c}\text { thermal } \\
\text { conductivity } \\
{\left[\mathbf{W} / \mathbf{m} \cdot{ }^{\circ} \mathrm{C}\right]}\end{array}$ & $\begin{array}{c}\text { specific heat } \\
{\left[\mathbf{J} / \mathbf{k g} \cdot{ }^{\circ} \mathrm{C}\right]}\end{array}$ & $\begin{array}{c}\text { Viscosity } \\
{[\mathrm{X}} \\
\left.\mathbf{1 0 ^ { - 5 }} \mathbf{k g} / \mathbf{m} \cdot \mathbf{s}\right]\end{array}$ \\
\hline-20 & 0.02281 & 1005.74 & 1.620 \\
\hline 0 & 0.02436 & 1005.90 & 1.722 \\
\hline 20 & 0.02587 & 1006.36 & 1.821 \\
\hline 27 & 0.02640 & 1006.60 & 1.854 \\
\hline 35 & 0.02699 & 1006.92 & 1.893 \\
\hline 45 & 0.02772 & 1007.39 & 1.940 \\
\hline
\end{tabular}

Table 4. Physical properties of seawater in atmospheric pressure at North Atlantic Ocean [29]

\begin{tabular}{|c|c|c|c|}
\hline $\begin{array}{c}\text { temperature } \\
{\left[{ }^{\circ} \mathrm{C}\right]}\end{array}$ & $\begin{array}{c}\text { thermal } \\
\text { conductivity } \\
{\left[\mathrm{W} / \mathrm{m} \cdot{ }^{\circ} \mathrm{C}\right]}\end{array}$ & $\begin{array}{c}\text { kinematic } \\
\text { viscosity } \\
{[\times} \\
\left.10^{-6} \mathrm{~m}^{2} / \mathrm{s}\right]\end{array}$ & $\begin{array}{l}\operatorname{Pr} \\
{[-]}\end{array}$ \\
\hline 0 & 0.5695 & 1.8540 & 13.355 \\
\hline 10 & 0.5865 & 1.3600 & 9.520 \\
\hline 20 & 0.6015 & 1.0505 & 7.155 \\
\hline 30 & 0.6155 & 0.8425 & 5.600 \\
\hline 40 & 0.6280 & 0.6945 & 4.515 \\
\hline 45 & 0.6335 & 0.6403 & 4.125 \\
\hline
\end{tabular}

\section{CALCULATION OF BOIL-OFF RATE (BOR)}

BOG in the LNG tank is generated by evaporation due to heat transfer during the transportation, local pressure change due to sloshing, heat input during loading \& unloading process, and other inherent disturbances. The most influential factor in the evaporation of BOG during the maritime travel period of LNG ships is the heat penetration into the tank. The evaporation rate is generally evaluated by calculating BOR, which signifies the percent of evaporated LNG per day with respect to the initial LNG loaded amount. Assuming all the penetrated heat is used for the evaporation of LNG for one day, BOR can be expressed as shown in Equation (1) [30]:

$$
\text { Boil }- \text { off Rate }(B O R)=\frac{Q_{l e a k} \times 3600 \times 24}{\rho_{L N G} \times V_{L N G} \times \lambda} \times 100
$$

Where, $\mathrm{Q}_{\text {leak }}$ represents the heat flow [W] that penetrates into LNG in the tank, $\rho_{L N G}$ is the density of LNG $\left[\mathrm{kg} / \mathrm{m}^{3}\right]$ 
$V_{\mathrm{LNG}}$ is the volume of $\mathrm{LNG}\left[\mathrm{m}^{3}\right]$, and $\lambda$ represents the heat for vaporization of $\mathrm{LNG}[\mathrm{J} / \mathrm{kg}$ ]. The tank is assumed to be filled with LNG to $98 \%$ of the capacity, and the remaining $2 \%$ with NG. The density of LNG, at atmospheric pressure and $-163^{\circ} \mathrm{C}$, is $425 \mathrm{~kg} / \mathrm{m}^{3}$ and the heat of vaporization is $511 \mathrm{~kJ} / \mathrm{kg}$.

\section{NUMERICAL APPROACH}

\section{GOVERNING EQUATION}

A numerical approach is adopted to solve the conductive and convective heat transfer as defined in the problem definition. The numerical calculations are performed using FLUENT, which is a commercial CFD software. In fluid flow, the governing equations for mass, momentum and energy conservation can be expressed such that:

$$
\begin{aligned}
& \frac{\partial \rho}{\partial t}+\nabla \cdot(\rho \bar{v})=0 \text { (continuity equation) } \\
& \frac{\partial}{\partial t}(\rho \bar{v})+\nabla \cdot(\rho \bar{v} \bar{v})=-\nabla p+\nabla \cdot(\overline{\bar{\tau}})+\rho \bar{g} \\
& \text { (momentum equation) } \\
& \frac{\partial}{\partial t}(\rho E)+\nabla \cdot(\rho \bar{v} E)=-\nabla \cdot \bar{q}-\nabla \cdot(\mathrm{P} \bar{v})+\nabla \cdot(\overline{\bar{\tau}} \cdot \bar{v})+ \\
& \rho \bar{v} \cdot \bar{g} \\
& \text { (energy equation) }
\end{aligned}
$$

Where $\rho$ is density of fluid, $\bar{v}$ is velocity vector, and $\overline{\bar{\tau}}=\mu\left[\left(\nabla \bar{v}+\nabla \bar{v}^{\mathrm{T}}\right)-\frac{2}{3} \nabla \cdot \bar{v} I\right]$ is the viscous stress tensor with I being the unit tensor. For Newtonian fluids viscous stresses only depend on the velocity gradient. The second right term in stress tensor represents the effect of volume dilation. $\rho \bar{g}$ term in equation (3) is the external body force. Equation (4) represents one of many forms of the conservation of energy, in which $\mathrm{E}$ is the total energy per unit mass, $\mathrm{E}=\mathrm{e}+\mathrm{V} 2 / 2$, e is the internal energy, and V2/2 is the kinetic energy. And $\rho \bar{v} \cdot \bar{g}$ term represents work done against viscous forces.

The flow behavior of air in BC and cofferdam ballast compartment is obtained by use of the realizable $\mathrm{k}-\varepsilon$ model, which is an improvement of the standard $\mathrm{k}-\varepsilon$ turbulence model. Turbulence modeling using Reynolds Averaged Navier-Stokes make uses of the Reynolds stresses term and in Cartesian tensor form it can be written as [31]:

$$
\begin{gathered}
-\rho \overline{u_{i}^{\prime}} \overline{u_{j}^{\prime}}=\mu_{t}\left(\frac{\partial u_{i}}{\partial x_{j}}+\frac{\partial u_{j}}{\partial x_{i}}\right)-\frac{2}{3}\left(\rho k+\mu_{t} \frac{\partial u_{k}}{\partial x_{k}}\right) \delta_{i j} \\
\mu_{\mathrm{t}}=\frac{\rho c_{\mu} k^{2}}{\varepsilon}
\end{gathered}
$$

Where, $\delta_{i j}$ represents Kronecker delta and $\mu_{\mathrm{t}}$ is the turbulent viscosity which is expressed by turbulent kinetic energy, $\mathrm{k}$, and turbulent dissipation rate, $\varepsilon$. The realizable $\mathrm{k}-\varepsilon$ model can make use of the standard $\mathrm{k}-\varepsilon$ model by using $\mathrm{C}_{\mu}$ as a variable in the numerical calculation, and this can be expressed as:

$$
\begin{gathered}
C_{\mu}=\frac{1}{A_{0}+A_{s} \frac{k U^{*}}{x}} \\
U^{*} \equiv \sqrt{S_{i j} S_{i j}+\widetilde{\Omega_{1 j} \widetilde{\Omega_{i j}}}} \\
\widetilde{\Omega_{1 j}}=\overline{\Omega_{1 j}}-\epsilon_{i j k} \omega_{k}-2 \epsilon_{i j k} \omega_{k}
\end{gathered}
$$

where $\overline{\Omega_{l j}}$ is the mean rate of rotation tensor viewed in a rotating reference frame with angular velocity, $\omega_{\mathrm{k}} . \mathrm{A}_{0}$ and $A_{s}$ have values of 4.04 and $\sqrt{6} \cos \phi$, respectively. The realizable $\mathrm{k}-\varepsilon$ model is able to give better estimated values than the standard $\mathrm{k}-\varepsilon$ model in complex separated flows and secondary flows involving rotation, boundary layers with pressure gradients, and recirculation [32].

\section{INSULATION PANEL (IP) SIMULATION}

In the numerical simulations of the octagonal pillar structure of KC-1 LNG tank for thermal analysis and subsequent $\mathrm{BOR}$ prediction, all the detailed configuration of the actual tank size, which include the materials of construction and specifications, should be considered in formulating the numerical grid. However, this requires solving the continuity, momentum and energy transport equations at each grid, and this is not easy task because of the large dimensional contrasts that exist between the sides of tank (27 46m) and the thickness of insulation layers $(1.5 \sim 230 \mathrm{~mm})$ as well as several conduction and convection heat transfer problems that must be dealt both inside and outside components of the tank. Capturing such dimensional contrasts would require as many as $10 \mathrm{e}+12$ grids which would not only consume enormous amount of CPU time due to highly details of the domain but there may be also difficulties in the convergence to proper limits, and therefore this approach is not deemed practical $[27,33]$. To simulate such complex physical phenomena of a LNG tank in a practical manner, an efficient numerical approach known as Reduced Order Models (ROMs) are adapted to simplify the insulation layers as the layers have the most complicated and detailed structures among the components of the LNG tank. A modified insulation, which comprises of the 5-layers of insulation (single combined membrane, top plywood, H-PUF, bottom plywood, mastic/ air) of the actual dimensions, is defined to compose only of H-PUF with a blowing agent. For the modified insulation and the inner hull as a whole, an equivalent thermal capacity are calculated using ROMs such that it can be incorporate into the simulation to reduce the size of the computational domain 
while providing numerical solutions that have minimal errors [27,34]. Since the H-PUF layer, which has the largest thickness among all layers in the insulation and low thermal conductivity, provides the greatest influence in determining the insulation performance, ROMs propose to extend it such that the calculated equivalent thermal conductivity $\left(\mathrm{k}_{\mathrm{eq}}\right)$ of the 'combined' insulation and inner hull can represent the actual thermal conductivities by a proportionality constant. The equivalent thermal conductivity, $\mathrm{k}_{\mathrm{eq}}$, of the combined section can be calculated as shown in Equation (10).

$$
k_{e q}=k_{H-P U F} \frac{q_{\text {ins }}}{q_{H-P U F}}=k_{H-P U F} C_{e q} \quad\left[\mathrm{~W} / \mathrm{m} \cdot{ }^{\circ} \mathrm{C}\right]
$$

Where, $q_{\text {ins }}$ is the heat flux $\left[\mathrm{W} / \mathrm{m}^{2}\right]$ calculated by numerical simulation of the 5-layered insulation and the inner hull as a whole, which incorporated the individual thermal conductivities in each layer including the inner hull. $q_{\mathrm{H}-\mathrm{puF}}$ represents the heat flux $\left[\mathrm{W} / \mathrm{m}^{2}\right]$ calculated by simulation of the modified insulation, in which the 5 layers of actual dimensions are assumed to be composed of only of H-PUF, and the inner hull. $\mathrm{k}_{\mathrm{eq}}$ is a value obtained by calculating the proportional constant $\mathrm{C}_{\mathrm{eq}}$ by applying the ratio of $q_{\text {ins }}$ to $\mathrm{q}_{\mathrm{H}-\mathrm{pur}}$ and then using the proportional constant as a correction factor to $\mathrm{k}_{\mathrm{H}-\mathrm{puF}}$.

(a) Grids of IP

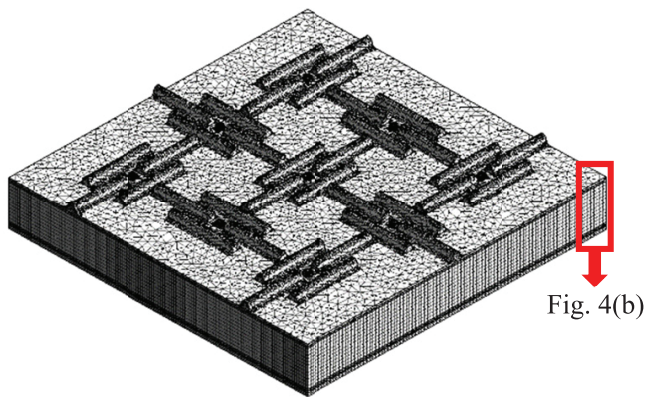

(b) Enlarged corner view of IP (size in $\mathrm{mm}$ )

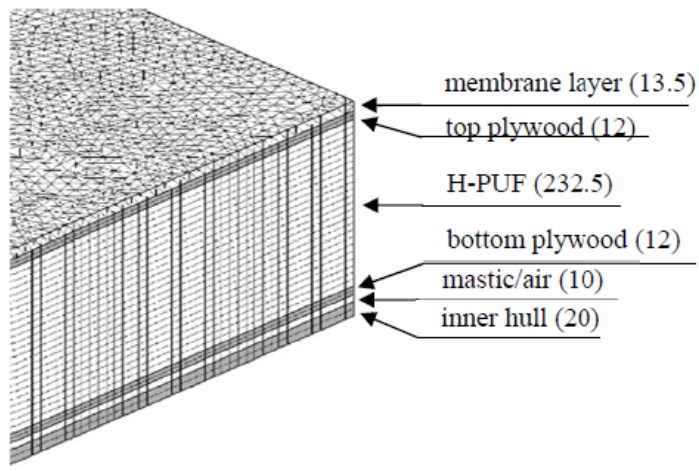

Fig. 4. Structural view and simulation grid of IP: (a) Grids of IP and (b) Enlarged corner view of IP.

For the numerical simulation, a 3 dimensional section (1920x1920x300) of the modified insulation with the inner hull, shown in Fig. 4(a), is further defined as an Insulation
Panel (IP) and the grids are generated. Fig. 4(b) shows an enlarged corner view of IP (insulation and inner hull), indicating the thickness of each layer from the inner hull to the membrane layer. The membrane corrugation has a curved type design, and the IP grids are configured to suitably represent the curved surface of the corrugation with unstructured grids (tetrahedron and hexahedron). The base element size of the IP grid is $10 \times 10 \mathrm{~mm}$ and IP is comprised of approximately $2 \times 106$ elements. The skewness average is 0.12 and the orthogonal quality minimum is $5.5842 \times 10^{-2}$. The boundary temperature of the membrane layer is defined to be at $-163^{\circ} \mathrm{C}$, whereas the inner hull is assumed to be at room temperature of $20^{\circ} \mathrm{C}$ [27].

Table 5. Results of $q_{\text {ins }}, q_{H-P U F}$, and $C_{e q}$ for 3 types of H-PUFs

\begin{tabular}{|c|r|r|r|}
\hline & \multicolumn{1}{|c|}{ HFC-365mfc } & \multicolumn{1}{c|}{ HFC-245fa } & \multicolumn{1}{c|}{ HFC-245fa-e } \\
\hline $\begin{array}{c}\mathbf{q}_{\text {ins }} \\
{\left[\mathbf{W} / \mathbf{m}^{2}\right]}\end{array}$ & 10.7466 & 10.4306 & 10.2990 \\
\hline $\begin{array}{c}\mathbf{q}_{\mathrm{H}-\mathrm{PUF}} \\
{\left[\mathbf{W} / \mathbf{m}^{2}\right]}\end{array}$ & 8.9283 & 8.6915 & 8.5519 \\
\hline $\mathrm{C}_{\text {eq }}[-]$ & 1.2036 & 1.2000 & $\mathbf{1 . 2 0 4 3}$ \\
\hline
\end{tabular}

Table 6. Results of $\boldsymbol{k}_{\text {eq }}$ for 3 types of H-PUFs vs. temperature

\begin{tabular}{|c|c|c|c|}
\hline $\begin{array}{c}\text { temperature } \\
{\left[{ }^{\circ} \mathrm{C}\right]}\end{array}$ & $\begin{array}{c}\mathbf{k}_{e q} \text { with HFC- } \\
\mathbf{3 6 5 \mathrm { mfc }} \\
{\left[\mathbf{W} / \mathbf{m} \cdot{ }^{\circ} \mathrm{C}\right]}\end{array}$ & $\begin{array}{c}\mathbf{k}_{\boldsymbol{e q}} \text { with HFC- } \\
\mathbf{2 4 5 f a} \\
{\left[\mathbf{W} / \mathbf{m} \cdot{ }^{\circ} \mathrm{C}\right]}\end{array}$ & $\begin{array}{c}\mathbf{k}_{e q} \text { of HFC- } \\
\mathbf{2 4 5 f a - e} \\
{\left[\mathbf{W} / \mathbf{m} \cdot{ }^{\circ} \mathrm{C}\right]}\end{array}$ \\
\hline-160 & 0.018476 & 0.018205 & 0.017751 \\
\hline-120 & 0.020185 & 0.020149 & 0.019642 \\
\hline-80 & 0.023146 & 0.022154 & 0.022304 \\
\hline-40 & 0.024687 & 0.023006 & 0.022990 \\
\hline-20 & 0.025241 & 0.023834 & 0.023929 \\
\hline 20 & 0.029032 & 0.027962 & 0.027458 \\
\hline
\end{tabular}

The computer CPU specification used for the numerical simulation is Intel(R) $2.1 \mathrm{GHz}$ Xeon processor. From the simulation of the IP grids, the calculated results of $\mathrm{q}_{\text {ins }}$, $\mathrm{q}_{\mathrm{H}-\mathrm{pup}}$ and $\mathrm{C}_{\mathrm{eq}}$ are shown in Table 5 , and the calculated $\mathrm{k}_{\mathrm{eq}}$ for 3 different H-PUFs, each with a different blowing agent, are shown in Table 6. Calculated $\mathrm{C}_{\mathrm{eq}}$ values are 1.2036, 1.200, and 1.2043 for using HFC-365mfc, HFC-245fa, and HFC$245 \mathrm{fa}-\mathrm{e}$ as the H-PUF layer, respectively. The results show that thermal resistance of the actual insulation with inner hull is approximately $20 \%$ lower than the modified insulation, which is composed of H-PUF only, with the inner hull.

Fig. 5 presents the result of the IP simulation for the modified insulation with HFC-245fa, which has an intermediate thermal conductivity among the three H-PUF. The results show the temperature profiles of $q_{\text {ins }}$ and $\mathrm{q}_{\mathrm{H} \text { - }}$ pup respect to the insulation thickness, when the temperatures of ballast compartment and LNG inside the tank are $20^{\circ} \mathrm{C}$ and $-163^{\circ} \mathrm{C}$ , respectively. The black dotted lines represent $q_{\text {ins }}$ and the red solid lines represent $q_{H-p u p}$ As seen in the figure, $q_{H-p U P}$ decreases linearly in all layers of the insulation, while $\mathrm{q}_{\text {ins }}$ is 
linear in the H-PUF layer, but exhibits a curved profile within the mastic/air, bottom and top plywood layers. The profile of $q_{\text {ins }}$ shows that the temperature drops within the inner hull, the membrane layer, the top plywood, bottom plywood, and mastic/air are $0.020^{\circ} \mathrm{C}, 0.022^{\circ} \mathrm{C}, 2.04^{\circ} \mathrm{C}, 2.01^{\circ} \mathrm{C}$, and $0.03^{\circ} \mathrm{C}$, respectively. The temperature drop within the $\mathrm{H}-\mathrm{PUF}$ layer is $178.88^{\circ} \mathrm{C}$, which indicates that the insulation performance is 97.74\% of KC-1 insulation including the inner hull. Therefore, the thermal conductivity and thickness of H-PUF are two important factors in determining the insulation performance in LNG tank design. The $\mathrm{k}_{\mathrm{eq}}$ values for the 3 types of $\mathrm{H}-\mathrm{PUF}$ are then applied to the overall $1 / 4$ tank structure cases exposed separately to the IGC and USCG conditions.

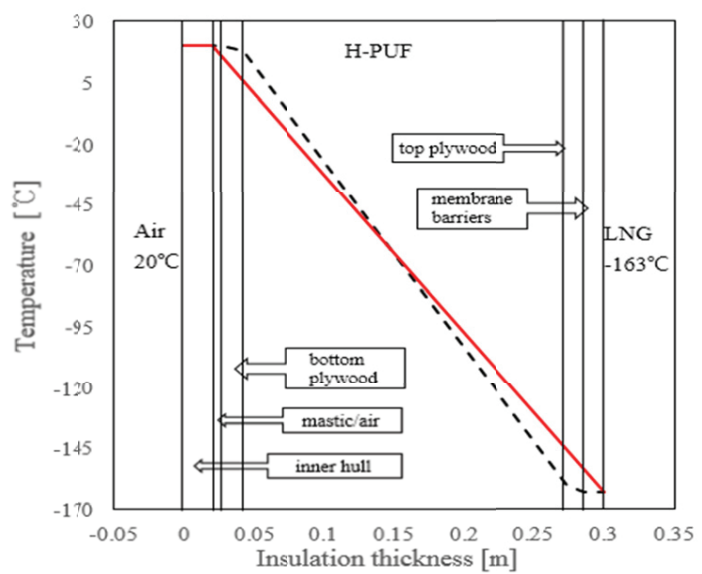

Fig. 5. Temperature profile of KC-1 insulation (black dot: results of $\boldsymbol{q}_{\text {ins }}$, red solid: results of $\boldsymbol{q}_{\mathrm{H}-\mathrm{PUF}}$ )

\section{D SIMULATION OF KC-1 LNG TANK}

For the 3D simulation of the KC-1 LNG tank, the $1 / 4$ tank structure of no.3 LNG tank, as shown in Fig. 6, is defined as the numerical analysis domain due to the symmetric boundary conditions that exist for the tank. From the IP simulation, calculated $\mathrm{k}_{\mathrm{eq}}$ of a section of modified insulation with the inner hull, which has a dimension of 1920x1920x300 $\mathrm{mm}$, is then integrated to the overall $1 / 4$ tank structure for the numerical simulations.

The figure shows the view of components and numerical grids of the $1 / 4 \mathrm{KC}-1$ LNG tank structure, and the compartments and surfaces of components of the tank structure are numbered and they are presented in Table 7.

Fig. 6(a) shows the structural view of the ballast compartment (BC), the surface of the ballast compartment Inner Hull (BCIHS), and the surface of the cofferdam inner hull (CIHS) of the $1 / 4$ tank. Here, the component numbers, $1 \sim 6$, indicate the six separate compartments or surfaces of corresponding components according to the levels of tank, from the top to the bottom. For example, BC-1 6 represents the six separate compartments of BC, each occupied by air, between the outer and inner hulls. Likewise, BCIHS1 6 represents the six separate surfaces of the inner hull corresponding to BC-1 6. From the top to the bottom, the components are numbered 1 6 representing top, top side, mid side (air), mid side (seawater), bottom side, and bottom of the tank. Mid side (air) and mid side (seawater) represent the compartments where the exterior of the outer hull of the BC makes contacts with the air and seawater of the outer tank, respectively. The boundary line separating BC-3 and BC-4 are based on the scantling draught, with the assumption that the exterior of the outer hulls of $\mathrm{BC}-1$ to $\mathrm{BC}-3$ are exposed to air and that of BC- 4 to $\mathrm{BC}-6$ are exposed to seawater. Fig. 6(b) illustrates structural views of the cofferdam, the cofferdam ballast compartment (CBC), and the cofferdam inner hull inner surface (CIHS). The cofferdam, numbered 19, is the structure between the LNG tanks mounted on the LNG

Table 7. Names of compartments and surfaces of components in KC-1 LNG tank

\begin{tabular}{|l|c|c|c|c|}
\hline \multicolumn{1}{|c|}{ section } & $\begin{array}{c}\text { ballast compartment } \\
\text { (BC) } \\
\text { [ballast space] }\end{array}$ & $\begin{array}{c}\text { ballast compartment } \\
\text { inner hull } \\
\text { (BCIHS) } \\
\text { [surface] }\end{array}$ & $\begin{array}{c}\text { cofferdam ballast compartment } \\
\text { (CBC) } \\
\text { [ballast space] }\end{array}$ & $\begin{array}{c}\text { cofferdam } \\
\text { inner hull } \\
\text { (CIHS) } \\
\text { [surface] }\end{array}$ \\
\hline top & $1:$ BC-1 & $7:$ BCIHS-1 & $13:$ CBC-1 & $20:$ CIHS-1 \\
\hline top side & $2:$ BC-2 & $8:$ BCIHS-2 & $14:$ CBC-2 & $21:$ CIHS-2 \\
\hline mid side (air) & $3:$ BC-3 & $9:$ BCIHS-3 & $15:$ CBC-3 & 22: CIHS-3 \\
\hline mid side (seawater) & $4:$ BC-4 & $10:$ BCIHS-4 & $16:$ CBC-4 & $23:$ CIHS-4 \\
\hline bottom side & $5:$ BC-5 & $11:$ BCIHS-5 & $17:$ CBC-5 & $24:$ CIHS-5 \\
\hline bottom & $6:$ BC-6 & $12:$ BCIHS-6 & $18:$ CBC-6 & $25:$ CIHS-6 \\
\hline & & & $19:$ cofferdam & \\
\hline
\end{tabular}

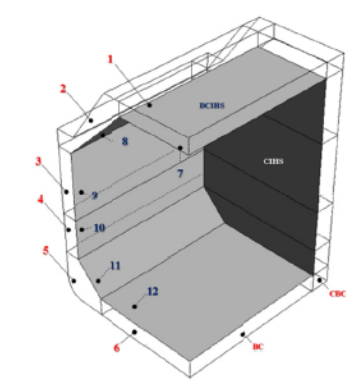

(a) Structural view of $B C, B C I H S$, and $C I H S$ without insulation
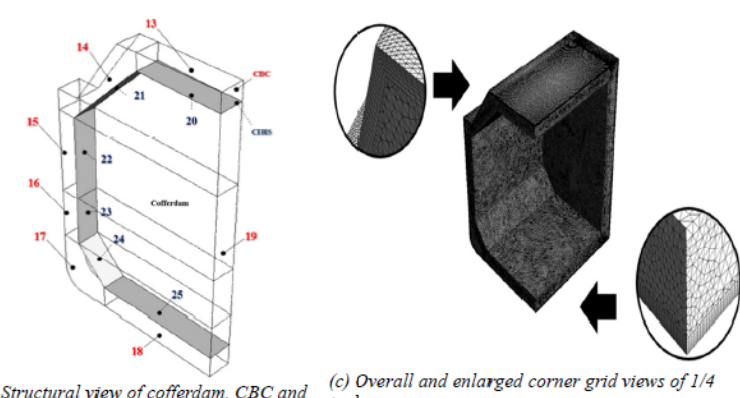

(b) Structural view of coffer without insulation

Table 7. Names of compartments and surfaces of components in KC-1 LNG tank 
Table 8. Grid quality validation for coarse, base and fine grids

\begin{tabular}{|c|c|c|c|c|c|c|c|}
\hline $\begin{array}{c}\text { grid type of } \\
\text { tank structure }\end{array}$ & $\begin{array}{c}\text { grid edge } \\
\text { size } \\
{[\mathrm{mm}]}\end{array}$ & $\begin{array}{c}\text { number of } \\
\text { grid elements }\end{array}$ & $\begin{array}{c}\text { average } \\
\text { skewness } \\
{[-]}\end{array}$ & $\begin{array}{c}\text { minimum } \\
\text { orthogonal } \\
\text { quality } \\
{[-]}\end{array}$ & $\begin{array}{c}\text { maximum } \\
\text { aspect ratio } \\
{[-]}\end{array}$ & $\begin{array}{c}\text { average } \\
\text { heat flux } \\
{\left[\boldsymbol{W} / \mathbf{m}^{2}\right]}\end{array}$ & $\begin{array}{c}\text { relative error } \\
\text { based } \\
\text { on base grid } \\
{[\%]}\end{array}$ \\
\hline coarse & 450 & $1,215,625$ & 0.2469 & 0.2117 & 35.398 & 14.4300 & 0.90 \\
\hline base & 300 & $2,810,868$ & 0.2374 & 0.1760 & 29.509 & 14.3068 & - \\
\hline fine & 150 & $9,306,533$ & 0.2369 & 0.1752 & 20.405 & 14.2647 & -0.29 \\
\hline
\end{tabular}

carriers. The component numbers $13 \sim 18$ show the CBCs-1 6, and the numbers $20-25$ show CIHS-1 6. The convective and conductive heat transfers to the air and steel in the closed spaces of the $\mathrm{BC}$ and $\mathrm{CBC}$ are considered, while neglecting the radiation heat transfer.

Fig. 6(c) shows the numerical grids of the $1 / 4$ tank structure for the numerical simulation. The tank's enlarged corner view represents the grids that are divided into seven layers to represent the air near the inner surface of outer hull in a prism grid configuration to capture the turbulence effect of the air in BC. The thickness growth rate of the grid layers for the air is set constant at 1.06. Since the tank is composed of corners and vertically asymmetric structures, the 1/4 tank structure is constructed with unstructured grids of approximately $2.8 \times 10^{6}$ elements, consisting of tetrahedrons, hexahedrons and prisms with grid edge size of $300 \mathrm{~mm}$. The grid quality had a skewness average of 0.237 and an orthogonal quality minimum of 0.176 .

In the numerical simulation, the Finite Volume Method (FVM) method with the double precision solver is used to maximize the number of significant digits needed in the analysis. Air in BC is assumed to be an incompressible ideal gas, and the following the turbulence model and discretization method are used: 1) In consideration of the air turbulence effect in the compartment, the realizable $\mathrm{k}-\varepsilon$ model is used as the turbulence model. For the turbulence effect on the compartment wall the enhanced wall treatment method is used, reflecting the thermal effects. 2) The pressure-based solver is used the solver type. 3) The pressure-velocity coupling scheme is applied with the Pressure Implicit Splitting of Operator (PISO) algorithm. 4) Spatial discretization is based on Least Squares Cell, pressure is based on PRESTO!, and energy and momentum are calculated by 2 nd order upwind, and turbulent kinetic energy and turbulent dissipation rate are applied with the Quadratic Upstream Interpolation for Convective Kinematics (QUICK) scheme. Since the tanks mounted on LNG carriers have height, length and width dimensions of several tens of meters, the Rayleigh number (Ra) can be considerably large. Therefore, PRESTO! scheme is used to simulate the high $\mathrm{Ra}$ in natural convection applied in the momentum conservation equation[9,35]. For the convergence check of the iterative solution, $10^{-6}$ for the energy term, and $10^{-4}$ for the continuity and velocity terms in the $x-y-z$ coordinate direction are used.

Numerical validation is performed through grid dependency prior to the full scale numerical thermal analysis of the $1 / 4 \mathrm{KC}-1 \mathrm{LNG}$ tank. To verify the grid dependency, 3 tanks are formulated with coarse $(450 \mathrm{~mm})$, base $(300 \mathrm{~mm})$, or fine $(150 \mathrm{~mm})$ grids, in which the grid edge size of the outer and inner hulls of components and insulation comprising the tank's entire structure is kept constant in each case. In all 3 tank cases, the growth rate of the edge size for the air layers of outer hull is applied constant at 1.06, and in the H-PUF layer of the insulation used HFC-245fa as the blowing agent. The validity of the base grid size is verified by the simulated heat flux results for each tank case as shown in Table 8 . The relative error calculated by the average heat flux based on the base grid simulation is $0.9 \%$ and $-0.29 \%$ for coarse and fine grids, respectively. Coarse grid simulation results show that the CPU time is approximately $1 / 2$ of that of the base grid case and 5 times faster than the fine, but a higher relative error of $0.9 \%$ compared to the base case. On the other hand, the fine grid case shows a low relative error of $-0.29 \%$, but the required CPU time is 2.5 times higher when compared to the base case. Therefore, comparing the results of the relative error and convergence time of the heat flux simulations, the optimal grid size is the base grid size of $300 \mathrm{~mm}$.

The external thermal boundary condition of the tank is defined using IGC (air: $45^{\circ} \mathrm{C}$, seawater: $32^{\circ} \mathrm{C}$ ) and USCG (air: $-18^{\circ} \mathrm{C}$, seawater: $0^{\circ} \mathrm{C}$ ) conditions for the thermal analysis. Since the air temperature inside the cofferdam can be lowered to approximately $-40^{\circ} \mathrm{C}$ due to the extremely low temperature of LNG, cold brittleness phenomenon may occur in the inner hull steel, it is assumed that the temperature inside the cofferdam is held constant at $5^{\circ} \mathrm{C}$ through a heating pipe or coil in each of the condition [22]. In calculating the heat transfer coefficient for the external tank's forced convection thermal condition, the linear velocity of air is assumed to be at 19.5 knots, and the equation is shown as follows [21].

$$
N u_{L}=\frac{h_{L} L}{k_{f}}=0.037 R e^{4 / 5}(P r)^{1 / 3}
$$

Where $\mathrm{h}_{\mathrm{L}}$ is the convective heat transfer coefficient, $\mathrm{L}$ is the characteristic length, and $\mathrm{k}_{\mathrm{f}}$ is the thermal conductivity of the air or seawater. The temperatures of the LNG and NG inside the tank is defined based on the interior heights of the tank, with LNG and NG in contact with $98 \%$ and $2 \%$ loaded tank levels, respectively. The temperatures are set at constant values of $-163^{\circ} \mathrm{C}$ and $-158^{\circ} \mathrm{C}$, for LNG and NG, respectively, which are assumed to be maintained throughout the simulation. In addition, the air in the $\mathrm{BC}$ is assumed to be at room temperature of $20^{\circ} \mathrm{C}$. In this study, the temperature distribution and BOR prediction of three tank cases, each comprised of one of three H-PUFs (HFC-365mfc, HFC-245fa 
and HFC-245fa-e) layer in the insulation, are exposed to each of IGC and USCG conditions, a total of six tank cases is simulated to examine the performance of $\mathrm{KC}-1$ insulation.

\section{RESULT AND DISCUSSION}

\section{RESULT OF IGC AND USCG CONDITION}

In this study, each of three types of environmentally friendly H-PUFs (blown by HFC-365mfc, HFC-245fa and HFC-245fa-e) is applied as a layer of the tank insulation to perform the numerical simulation. A total of six tank cases exposed to the environment conditions, IGC and USCG, are defined as IGC-1 to 3 and USCG-1 to 3, respectively. Among the tanks, the tank structure containing HFC-245fa with an intermediate thermal conductivity is set as the base tank cases, namely IGC-2 and USCG-2. The temperature of the external air of the tank and the seawater is defined to be $45^{\circ} \mathrm{C}$ and $32^{\circ} \mathrm{C}$, and $-18^{\circ} \mathrm{C}$ and $0^{\circ} \mathrm{C}$ for the IGC and USCG, respectively. The temperature distribution results of the tank components and associated sections for each of the tank case are shown in Table 9, and temperature contours of base tanks are shown in Fig. 7 and Fig. 8 for IGC and USGC cases, respectively.

Performance of KC-1 insulation on IGC-2, the base tank for IGC condition, is evaluated between the outer hull of BC-1 (1st ballast component) and the surface of membrane layer as it has the largest cross-sectional temperature drop. The temperature drop between the outer hull of BC-1 $\left(45^{\circ} \mathrm{C}\right)$ and the corresponding inner hull $\left(39.55^{\circ} \mathrm{C}\right)$, BCIHS- 1 , is $5.45^{\circ} \mathrm{C}$, while the drop between BCIHS-1 and the membrane layer $\left(-163^{\circ} \mathrm{C}\right.$ is $202.55^{\circ} \mathrm{C}$. The results demonstrate that $97.38 \%$ of the temperature drop occurs between BCIHS-1 and the membrane layer. In the USCG-2 case, the base tank for USCG condition, the largest cross-sectional temperature drop occurred between the outer hull of 5th ballast compartment section (BC-5) and the surface of membrane layer. While the temperature drop between the outer hull of $\mathrm{BC}-5\left(0^{\circ} \mathrm{C}\right)$ and BCIHS $-5\left(-1.39^{\circ} \mathrm{C}\right)$ is $1.39^{\circ} \mathrm{C}$, the greatest temperature drop formed between BCIHS-5 and the membrane layer is $161.63^{\circ} \mathrm{C}$. Thus $99.15 \%$ of the effective insulation comes from this region.

In the temperature distribution of the IGC-2, the highest temperature is at $\mathrm{BC}-1\left(39.55^{\circ} \mathrm{C}\right)$ amongst all ballast compartments (BC), while the lowest resulted at BC-6 $\left(29.07^{\circ} \mathrm{C}\right)$. In the Ballast Compartment Inner Hull Surface (BCIHS), the highest temperature is at BCIHS-1 $\left(37.71^{\circ} \mathrm{C}\right)$ while the lowest temperature is at BCIHS-6 $\left(27.68^{\circ} \mathrm{C}\right)$. In the sections are located below the seawater level, BC-4 6 and BCIHS-4 6, the highest temperature resulted in BC-4 $\left(29.33^{\circ} \mathrm{C}\right)$ and BCIHS-5 $\left(28.03^{\circ} \mathrm{C}\right)$, respectively. In the Cofferdam Ballast Compartment (CBC) sections the highest temperature predicted is at $\mathrm{CBC}-2\left(38.06^{\circ} \mathrm{C}\right)$ rather than at CBC $-1\left(31.63^{\circ} \mathrm{C}\right)$ while the lowest is at CBC-6 $\left(24.10^{\circ} \mathrm{C}\right)$. In particular, $\mathrm{CBC}-3$ formed a relatively higher temperature than CBC-1. Similar trend of temperature distribution is also observed in the Cofferdam Inner Hull Surface (CIHS) sections. This results are primarily due to the given boundary conditions and different contact surface areas that adjoin the sections of cofferdam, cofferdam compartment and ballast compartment as shown in Fig. 6.

In contrast to the temperature distribution of IGC-2, in the USCG-2 the highest temperature among the $\mathrm{BC}$ sections is at $\mathrm{BC}-5\left(-0.31^{\circ} \mathrm{C}\right)$, while the lowest is observed at $\mathrm{BC}-1\left(-17.51^{\circ} \mathrm{C}\right)$. The results of BCIHS sections are similar to $\mathrm{BC}$ sections in that the highest temperature is predicted at BCIHS-5 $\left(-1.39^{\circ} \mathrm{C}\right)$, while the lowest is at BCIHS $-1\left(-18.46^{\circ} \mathrm{C}\right)$. On the other hand, the temperature distributions of $\mathrm{CBC}$ and $\mathrm{CIHS}$ sections are slightly different from those of BC and BCIHS sections: the highest temperature predictions are at $\mathrm{CBC}-6$ $\left(0.9^{\circ} \mathrm{C}\right)$ and CIHS $-6\left(3.06^{\circ} \mathrm{C}\right)$, while the lowest are at $\mathrm{CBC}-2$ $\left(-15.83^{\circ} \mathrm{C}\right)$ and $\mathrm{CIHS}-2\left(-5.38^{\circ} \mathrm{C}\right)$.

In both IGC and USCG conditions, the each component's temperature difference between each tank cases is not significant. For example, the temperature difference of BC- 1 components between IGC- 2 and IGC- 3 is $0.01^{\circ} \mathrm{C}$ and $0.08^{\circ} \mathrm{C}$ between IGC-1 and IGC-2. On the other hand, the temperature difference of each $\mathrm{BC}-5$ between USCG-2 and USCG-3 is $0.00^{\circ} \mathrm{C}$ and $0.02^{\circ} \mathrm{C}$ between USCG-1 and USCG-2. The above results show that the each component's temperature difference between IGC-1 and 2 is relatively higher than that between IGC-2 and 3, but it is not remarkable.

According to the aforementioned results, the temperature distribution of the LNG tanks in IGC and USCG conditions tends to be low when the thermal conductivity of H-PUF becomes higher (i.e. lower insulation performance). This is the result of setting the cofferdam air to a constant temperature value of $5^{\circ} \mathrm{C}$. As opposed to IGC condition, the USCG indicates that the $5^{\circ} \mathrm{C}$ value in the cofferdam has a relatively larger influence on the resulting temperature distribution. Therefore, the components of the tank are designed more with the consideration of strengthening individual functions (ballast water space, hull shape maintenance, etc.) and safety, such as dealing with the LNG leakage phenomenon, rather than the enhancing the insulation performance of the LNG tank. Therefore, an effective LNG tank design to meet the insulation performance requirements, requires low thermal conductivity of material elements of the insulation.

The temperature contours of the each of the base tank cases (IGC-2 and USCG-2), for IGC and USCG conditions, are shown in Fig. 7 and 8, respectively. In the sub-figures, a component of the tank is voided purposely for easier viewing. For example, Fig. 7(a) and 8(a) show the contours for BC, CBC and the cofferdam without the insulation component. The contours for the remaining tank without $\mathrm{CBC}$ component are presented in Fig. 7(b) and 8(b), while Fig. 7(c) and 8(c) show temperature contours of $\mathrm{CBC}$ and the cofferdam except for BC. Fig. 7(b) shows the results of applying the IGC condition to the base tank which shows that the higher the section of a component of tank, the higher the temperature it predicted. Fig 8(b) reflects the results of USCG condition: the closer a section is to $\mathrm{BC}-5$, which is near the bottom part of the tank, the higher the temperature. It should be noted that 
Table 9. Temperature distribution results of various components of tank for 6 tank cases

\begin{tabular}{|c|c|c|c|c|c|c|c|}
\hline $\begin{array}{l}\text { name of } \\
\text { components }\end{array}$ & tank case & IGC-1 & IGC-2 & IGC-3 & USCG-1 & USCG-2 & USCG-3 \\
\hline \multirow{6}{*}{$\begin{array}{l}\text { ballast } \\
\text { compartment } \\
(\mathrm{BC})\end{array}$} & BC-1 & 39.47 & 39.55 & 39.56 & -17.54 & -17.51 & -17.51 \\
\hline & BC-2 & 39.33 & 39.38 & 39.39 & -16.81 & -16.79 & -16.78 \\
\hline & BC-3 & 36.81 & 36.88 & 36.89 & -15.72 & -15.69 & -15.69 \\
\hline & BC-4 & 29.28 & 29.33 & 29.33 & -2.52 & -2.49 & -2.48 \\
\hline & BC-5 & 29.29 & 29.32 & 29.32 & -0.33 & -0.31 & -0.31 \\
\hline & BC-6 & 29.02 & 29.07 & 29.08 & -0.64 & -0.61 & -0.60 \\
\hline \multirow{5}{*}{$\begin{array}{l}\text { ballast compartment } \\
\text { inner hull surface (BCIHS) }\end{array}$} & BCIHS-1 & 37.58 & 37.71 & 37.73 & -18.52 & -18.46 & -18.44 \\
\hline & BCIHS-2 & 37.37 & 37.48 & 37.50 & -17.95 & -17.89 & -17.88 \\
\hline & BCIHS-3 & 35.06 & 35.19 & 35.21 & -16.63 & -16.57 & -16.55 \\
\hline & BCIHS-4 & 27.70 & 27.80 & 27.82 & -3.73 & -3.66 & -3.64 \\
\hline & BCIHS-5 & 27.95 & 28.03 & 28.04 & -1.46 & -1.39 & -1.38 \\
\hline \multirow{7}{*}{$\begin{array}{l}\text { cofferdam } \\
\text { ballast } \\
\text { compartment (CBC) }\end{array}$} & BCIHS-6 & 27.57 & 27.68 & 27.69 & -1.78 & -1.70 & -1.68 \\
\hline & CBC-1 & 31.59 & 31.63 & 31.64 & -12.38 & -12.36 & -12.35 \\
\hline & CBC-2 & 38.01 & 38.06 & 38.07 & -15.85 & -15.83 & -15.83 \\
\hline & CBC-3 & 35.85 & 35.91 & 35.92 & -14.66 & -14.63 & -14.63 \\
\hline & CBC-4 & 27.65 & 27.70 & 27.70 & -1.06 & -1.04 & -1.03 \\
\hline & CBC-5 & 27.49 & 27.52 & 27.52 & 0.45 & 0.46 & 0.47 \\
\hline & CBC-6 & 24.07 & 24.10 & 24.11 & 0.88 & 0.90 & 0.90 \\
\hline \multirow{6}{*}{$\begin{array}{l}\text { cofferdam } \\
\text { inner Hull surface(CIHS) }\end{array}$} & CIHS- 1 & 16.70 & 16.71 & 16.72 & -3.71 & -3.70 & -3.70 \\
\hline & CIHS-2 & 19.80 & 19.82 & 19.83 & -5.39 & -5.38 & -5.38 \\
\hline & CIHS-3 & 19.01 & 19.04 & 19.04 & -4.55 & -4.53 & -4.53 \\
\hline & CIHS- 4 & 15.49 & 15.51 & 15.51 & 2.05 & 2.06 & 2.07 \\
\hline & CIHS-5 & 15.84 & 15.85 & 15.85 & 2.83 & 2.84 & 2.84 \\
\hline & CIHS-6 & 14.20 & 14.22 & 14.22 & 3.05 & 3.06 & 3.06 \\
\hline
\end{tabular}

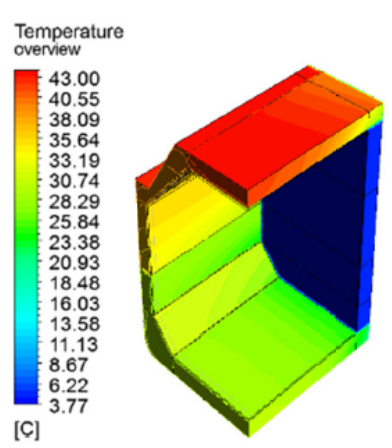

(a) Temperature contour less insulation

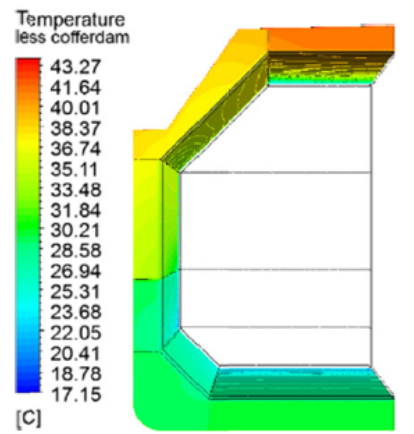

(b) Cross-sectional view less $C B C$ and cofferdam

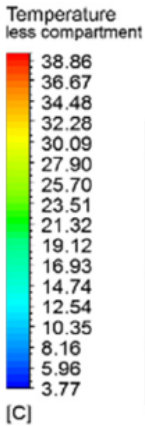

(c) Cross-sectional view less $B C$

Fig. 7. Temperature contour of base tank case, IGC-2, for IGC condition

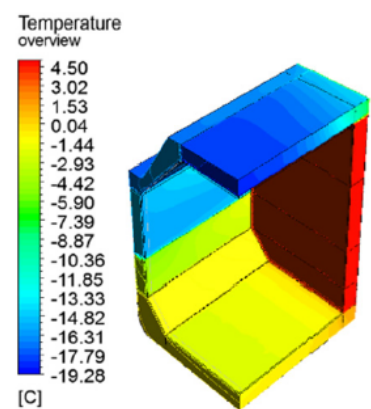

(a) Temperature contour less insulation

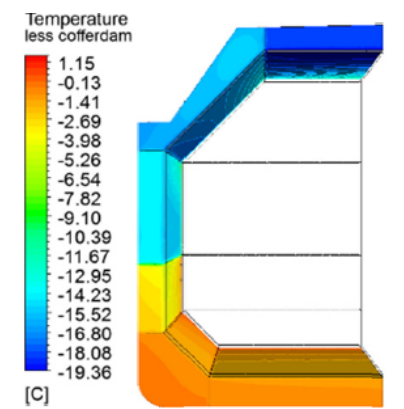

(b) Cross-sectional view less $C B C$ and cofferdam

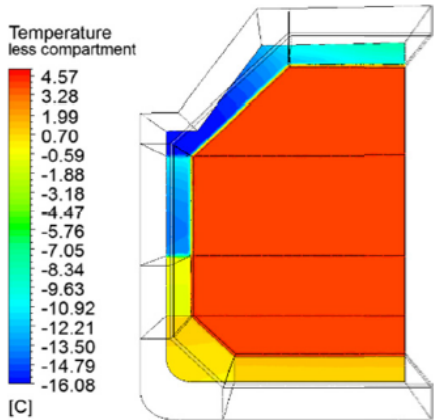

(c) Cross-sectional view less $B C$

Fig. 8. Temperature contour of base tank case, USCG-2, for USCG condition 
the air in the cofferdam is kept constant at $5^{\circ} \mathrm{C}$ and it is the lowest temperature in the IGC, while the air shows the highest temperature in the UGSC condition (see Fig. 7(a, c) and Fig. $8(\mathrm{a}, \mathrm{c}))$.

Fig. 9 shows the temperature $\operatorname{drop}(\Delta \mathrm{T})$ from the midpoint of the outer surface of $\mathrm{CBC}$, the surface adjoining $\mathrm{BC}$, to the corresponding midpoint of $\mathrm{BC}$ section of the base tank at few locations away from the surface in the normal direction. Fig. 9(a) shows results of negative $\Delta \mathrm{T}$ vs. the distance when the base tank is exposed to IGC condition. The IGC results for the BC- 1 and BC- 6 sections show relatively large $\Delta \mathrm{T}$ when the distance is within a close proximity of the surface of $\mathrm{CBC}$. The $\Delta \mathrm{T}$ curve exhibits an exponential decay as a function of the distance from the surface. In the sections of BC-2 5, the $\Delta \mathrm{T}$ decreased at a constant but moderate rate with the distance. In the base case exposed to the USGC, the results are positive $\Delta \mathrm{T}$ curves as shown in Fig. 9(b). The results of the USGC are similar to the IGC, however, $\Delta \mathrm{T}$ are positive rather than negative and the magnitudes are less pronounced. In $\mathrm{BC}-1$ and BC- 6 sections, the USGC results also show relatively large $\Delta T$ at the distance close to the surface of $\mathrm{CBC}$, but the $\Delta \mathrm{T}$ curves are inverted comparing to the IGC results. BC-2, BC-3 and $\mathrm{BC}-5$ showed a moderate increase of $\Delta \mathrm{T}$ at a constant rate with the distance, however, the $\Delta \mathrm{T}$ curve of $\mathrm{BC}-4$ surpasses that of BC- 6 at $13 \mathrm{~m}$ distance away from the surface, which then gradually decreases after reaching a peak near $20 \mathrm{~m}$ away. The $\Delta \mathrm{T}$ curves shown in Fig 9. are primarily due to the large heat transfer surface area of BC-1, BC-2 and BC- 6 than BC-3 5 as

well as the boundary conditions set forth by IGC and USCG conditions have significant effects on the thermal analysis to predict such temperature distributions.

\section{COMPARISON OF TEMPERATURE DISTRIBUTION RESULTS}

Table 10 shows the specifications of three membrane types of LNG tanks that have been studied by several researchers $[21,23,25,27]$. Most of the thermal analysis of tank used IGC and USCG conditions as the boundary conditions of tank. The LNG tank type that is mainly investigated are the Mark III and GT96, with the volume of tank ranging 34,001 - 49,391 $\mathrm{m}^{3}$ for Mark III and $40,436 \mathrm{~m}^{3}$ for GT96. In song et al. [23,25], Lee $[23,25]$, and the present study, the thermal boundary condition is assumed to be symmetrical, viewing from the mid-lines of the LNG tank in the longitudinal and latitudinal directions, thereby reducing the numerical domain to the $1 / 4$ of the actual tank structure for the analysis. While most assumed the main insulation layer is composed of perlite or Reinforced Polyurethane Foam (R-PUF) with a thickness range of $0.27-0.55 \mathrm{~m}$ and a double insulation structure, the $\mathrm{KC}-1$ insulation is designed with a single insulation structure with a thickness of $0.27 \mathrm{~m}$ and H-PUF is used as the main insulation layer.

Table 11 presents the summary of BC and BCIHS temperature distribution results of several other authors shown in Table 10, which includes the base tank case of this Table 10. Specification of LNG tank type used for thermal analysis of current study and others reported in scientific literature

\begin{tabular}{|l|c|c|c|c|c|c|}
\hline \multicolumn{1}{|c|}{ reference } & condition & type of tank & $\begin{array}{c}\text { tank volume } \\
{\left[\mathbf{m}^{\mathbf{3}}\right]}\end{array}$ & $\begin{array}{c}\text { total insulation thickness } \\
{[\mathbf{m}]}\end{array}$ & $\begin{array}{c}\text { main insulation } \\
{[-]}\end{array}$ & insulation structure \\
\hline $\begin{array}{l}\text { Heo and Jeon } \\
\text { [21] }\end{array}$ & IGC/USCG & Mark III & 40,449 & 0.54 & perlite & Double \\
\hline $\begin{array}{l}\text { Song et al. } \\
\text { [23] }\end{array}$ & IGC/USCG & Mark III & 34,001 & 0.55 & perlite & Double \\
\hline Lee [25] & IGC/USCG & GT-96 & 40,436 & 0.53 & R-PUF & Double \\
\hline $\begin{array}{l}\text { Miana et al. } \\
\text { (app.4)[27] }\end{array}$ & IGC & Mark III & 49,391 & 0.27 & H-PUF & Single \\
\hline present study & IGC/USCG & KC-1 & 48,280 & 0.27 & \\
\hline
\end{tabular}

Table 11. Comparison of temperature distribution results of BC and BCIHS for IGC and USCG conditions

\begin{tabular}{|c|c|c|c|c|c|c|c|c|c|c|}
\hline \multirow[b]{2}{*}{ reference } & \multirow{2}{*}{$\begin{array}{c}\text { conditio } \\
\mathrm{n}\end{array}$} & \multirow{2}{*}{$\begin{array}{c}\text { names of } \\
\text { components }\end{array}$} & \multirow{2}{*}{$\begin{array}{l}\text { top: } \\
\text { (1) }\end{array}$} & \multirow{2}{*}{$\begin{array}{l}\text { top side: } \\
\text { (2) }\end{array}$} & \multicolumn{3}{|c|}{ mid side } & \multirow{2}{*}{$\begin{array}{l}\text { bottom } \\
\text { side: } \\
(5)\end{array}$} & \multirow{2}{*}{$\begin{array}{l}\text { bottom: } \\
\text { (6) }\end{array}$} & \multirow[b]{2}{*}{ Cofferdam } \\
\hline & & & & & $\begin{array}{l}\text { air: } \\
(3)\end{array}$ & average & $\begin{array}{c}\text { seawater: } \\
\text { (4) }\end{array}$ & & & \\
\hline \multirow{4}{*}{$\begin{array}{l}\text { Heo and Jeon } \\
\text { [21] }\end{array}$} & \multirow{2}{*}{ IGC } & BC & 39.70 & 39.40 & 37.50 & & 31.50 & 29.00 & 27.70 & \multirow{2}{*}{5.00} \\
\hline & & BCIHS & 27.80 & 34.20 & 31.60 & & 26.20 & 23.90 & 23.03 & \\
\hline & \multirow{2}{*}{ USCG } & BC & -20.60 & -21.60 & -21.80 & & -10.80 & -3.00 & -3.90 & \multirow{2}{*}{-47.40} \\
\hline & & BCIHS & -26.83 & -25.60 & -24.80 & & -15.10 & -7.90 & -7.70 & \\
\hline \multirow{4}{*}{$\begin{array}{l}\text { Song et al. } \\
\text { [23] }\end{array}$} & \multirow{2}{*}{ IGC } & BC & 38.67 & 38.90 & \multicolumn{3}{|c|}{36.67} & 29.00 & 25.84 & \multirow{4}{*}{5.00} \\
\hline & & BCIHS & 32.44 & 31.24 & \multicolumn{3}{|c|}{29.10} & 21.91 & 20.02 & \\
\hline & \multirow{2}{*}{ USCG } & BC & -21.39 & -20.86 & \multicolumn{3}{|c|}{-20.02} & -4.35 & -4.65 & \\
\hline & & BCIHS & -25.58 & -26.01 & \multicolumn{3}{|c|}{-22.65} & -9.30 & -9.79 & \\
\hline \multirow{4}{*}{ Lee $[25]$} & \multirow{2}{*}{ IGC } & BC & 42.17 & 41.88 & \multicolumn{3}{|c|}{39.41} & 30.49 & 28.32 & \multirow{4}{*}{5.00} \\
\hline & & BCIHS & 40.11 & 39.60 & \multicolumn{3}{|c|}{36.90} & 26.95 & 25.28 & \\
\hline & \multirow{2}{*}{ USCG } & $\mathrm{BC}$ & -17.70 & -17.38 & \multicolumn{3}{|c|}{-14.74} & -2.72 & -2.28 & \\
\hline & & BCIHS & -18.35 & -18.60 & \multicolumn{3}{|c|}{-16.66} & -5.73 & -4.90 & \\
\hline \multirow{2}{*}{$\begin{array}{l}\text { Miana et al. } \\
\text { (app.4)[27] }\end{array}$} & \multirow{2}{*}{ IGC } & $\mathrm{BC}$ & 36.35 & 37.65 & \multicolumn{3}{|c|}{30.55} & 28.62 & 27.55 & \multirow{2}{*}{0.12} \\
\hline & & BCIHS & 25.90 & 30.24 & & 25.67 & & 23.15 & 23.09 & \\
\hline & & BC & 39.55 & 39.38 & 36.88 & & 29.33 & 29.32 & 29.07 & \\
\hline present study & $\mathrm{IGC}$ & BCIHS & 37.71 & 37.48 & 35.19 & & 27.80 & 28.03 & 27.68 & 500 \\
\hline (base tank) & USCG & $\mathrm{BC}$ & -17.51 & -16.79 & -15.69 & & -2.49 & -0.31 & -0.61 & 5.00 \\
\hline & . & BCIHS & -18.46 & -17.89 & -16.57 & & -3.66 & -1.39 & -1.70 & \\
\hline
\end{tabular}


study for the IGC and USCG conditions, IGC-2 and USCG2. The comparison of numerical simulation shows that the discrepancy in temperature can be considerably large due to the difference in the volume size, material and thickness of insulation, structure, component and compartment of the tank used as well as the calculation method used to treat the inner convection space, the outer and inner hull, and the heat transfer area. By referring to the conditions used in each author, the temperature results of each tank component are appropriately recalculated as an average value so that qualitative comparison is possible, minimizing the influence of various variables used in different studies.

Among temperature distribution results of BC for IGC condition that are presented in Table 11, Heo and Jeon [21] and the present study separated the compartments of $\mathrm{BC}$ exposed to air/seawater into two compartments: the compartments exposed to air and seawater are designated as BC-3 and $\mathrm{BC}-4$, respectively. In comparison of Heo and Jeon's work and the present work, the temperature differences between $\mathrm{BC}-3$ and $\mathrm{BC}-4$ are $-0.62^{\circ} \mathrm{C}$ and $-2.17^{\circ} \mathrm{C}$, respectively, and for BCIHS- 3 and BCIHS- 4 the differences are $3.59^{\circ} \mathrm{C}$ and $1.6^{\circ} \mathrm{C}$, respectively, showing that there is a good agreement between them. However, Song et al., Lee, and Miana et al. [23,25,27] did not separate BC that are in contact with air/seawater, so their results are simply represented by the average value (mid side $\mathrm{BC}$ ) and are excluded from the comparison.

For IGC condition, the maximum BC temperature difference against the base tank case (IGC-2) is found with BC- 6 of Song et al. [23], where the difference is $3.23^{\circ} \mathrm{C}$. Within BCIHS, the greatest difference is with BCIHS-1 of Miana et al. [27], and the difference is $11.81^{\circ} \mathrm{C}$. Such large difference is primarily due to differences in the method of treating convective heat transfer and grid formation in the interior surface of the outer hull, BC, and CBC of the tank, but also differences in the thermal conductivity of insulation materials, the temperature settings in the cofferdam, as well as approaches used in the numerical simulation.

In BC results of USCG condition, Lee [25] found a maximum temperature at BC- 6 while others, including present study, found a maximum at BC-5. Such results are also supported by other published works in addition to the authors discussed here in this study [36,37]. Comparing with the base case, the maximum $\mathrm{BC}$ temperature difference is $4.04^{\circ} \mathrm{C}$ with work of Song et al. [23] for BC-5, rather than BC-6 as seen in other cases. In BCIHS, the maximum difference is shown at BCIHS-5 with $7.91^{\circ} \mathrm{C}$, also with Song et al. [23]'s work. Such results are due to relatively a high constant value $\left(0.04 \mathrm{~W} / \mathrm{m}^{2}{ }^{\circ} \mathrm{C}\right)$ used for the thermal conductivity of PUF.

In comparison with the previous studies, the temperature distribution results of $\mathrm{BC}$ and BCIHS for the USCG condition generally showed a larger difference than the IGC condition as a whole. In the USCG condition the results showed that a lower temperature generally forms in a upper level ballast compartment while a higher temperature is predicted at a lower level ballast compartment, which is opposite from the IGC results. This effect is more pronounced as the separation of BC-3 and BC-4, which corresponds to the sea level, in effect lowered natural convective heat transfer within the compartment.

Miana et al. [27] predicted the air in the cofferdam as $0.12^{\circ} \mathrm{C}$ for the IGC condition, because the surface temperature of the inner hull in the cofferdam had a constant value of $5^{\circ} \mathrm{C}$. This is somewhat different from this study as the air in the cofferdam is set constant at $5^{\circ} \mathrm{C}$. In the results of USCG condition, Heo and Jeon [21] predicted the air in the cofferdam to be $-47.4^{\circ} \mathrm{C}$. Such large temperature difference exists because there were no heating coils present in the cofferdam to compensate the heat loss in the air when the temperature drops.

\section{COMPARISON OF BOR RESULTS}

Table 12 compares the BOR prediction results from the IGC/USCG conditions for the authors mentioned in Table 10. For the three different types of LNG tank with various tank capacities, the calculated BOR ranged from 0.0856 $0.129 \% /$ day. Although, it is idealistic to incorporate all the factors influencing physical properties of tank structure such as inner/outer hulls and supports, as well as insulation materials, air and LNG/NG into the numerical simulation for the thermal analysis of the LNG tank and subsequent calculation of BOR, in practice, however, it may be difficult to generate desired numerical solution in timely manner. While many of studies attempt to incorporate substantial amount of information of tank structure in their numerical calculations, most do not formulate computational cells for the LNG and NG volumes in the tank because the run time required to simulate such large number of numerical grids extends much time and difficulties that may arise in convergences to analyze such detailed domain that may not of interest. In fact, all the researchers under consideration assumed LNG to have a constant temperature between -162 and $-163^{\circ} \mathrm{C}$. Song et al. [23] and present study assumed LNG is at $-163^{\circ} \mathrm{C}$ and $98 \%$ and $\mathrm{NG}$ is at $-158^{\circ} \mathrm{C}$ and $2 \%$ filled by the volume. Heo and Jeon [21], Song et al. [23] and Lee [25] assumed that the thermal conductivity of the insulator is constant, while Heo and Jeon [21] assumed thermal conductivity of air/water varies with temperature. Both Miana et al. [27] and the present study calculated the thermal conductivities of the insulation and air/seawater as a function of the temperature. As shown in Table 12, the results of IGC condition for the studies for BOR predictions are less than $0.15 \% / d a y$, which is defined as the safety evaluation standard of IMO regulation. Miana et al. [27] predicted a lower BOR of $0.0856 \%$ /day by use of R-PUF in the insulation layer, which has relatively high thermal resistance.

Table 13 shows the results of BOR for all 6 tank cases in this study: 3 tank cases for IGC condition and 3 tanks for USCG condition. The USCG condition is more severe than the IGC condition because it is the condition used for evaluating the low temperature brittleness of the steel. Thus, the predicted BOR value in the USCG condition is lower than the results of IGC condition in all cases. In general, the BOR values are compared only for the IGC condition. The BOR predicted in the base tank case (H-PUF with HFC-245fa as 
the blowing agent), IGC-2, is calculated as $0.0927 \% /$ day. The maximum BOR predicted is $0.0964 \%$ / day for the case of IGC-1 that used HFC-365mfc as the blowing agent, while the minimum BOR predicted is $0.0921 \%$ /day for IGC-3 using HFC-245fa-e. The BOR predictions for all 6 tank cases sufficiently meet the IMO regulation of $0.15 \% /$ day as well as satisfying the KOGAS BOR limit of $0.12 \% /$ day. Therefore, KC-1 LNG tanks equipped with insulation comprising of H-PUF blown with an environmentally friendly refrigerant of low ODP have competitive edges both in design and production.

\section{Table 12. Comparison of BOR results for IGC condition}

\begin{tabular}{|c|c|c|c|c|c|}
\hline \multirow[b]{2}{*}{ reference } & \multicolumn{2}{|c|}{ thermal conductivity } & \multirow[b]{2}{*}{ condition } & \multirow{2}{*}{$\begin{array}{c}\text { heat flow } \\
{[\mathrm{W}]}\end{array}$} & \multirow{2}{*}{$\begin{array}{c}\text { BOR } \\
{[\% / \text { day }]}\end{array}$} \\
\hline & $\begin{array}{c}\text { insulation } \\
\text { materials }\end{array}$ & air/seawater & & & \\
\hline \multirow{2}{*}{$\begin{array}{l}\text { Heo and Jeon } \\
{[21]}\end{array}$} & \multirow{2}{*}{$\begin{array}{l}\text { constant } \\
\text { value }\end{array}$} & \multirow{2}{*}{ varying of $\mathrm{T}$} & IGC & 130,870 & 0.1290 \\
\hline & & & USCG & - & - \\
\hline \multirow{2}{*}{$\begin{array}{l}\text { Song et al. } \\
{[23]}\end{array}$} & \multirow{2}{*}{$\begin{array}{l}\text { constant } \\
\text { value }\end{array}$} & \multirow{2}{*}{$\begin{array}{l}\text { constant } \\
\text { value }\end{array}$} & IGC & 75,888 & 0.1003 \\
\hline & & & USCG & 65,268 & 0.0863 \\
\hline \multirow{2}{*}{$\begin{array}{l}\text { Miana et al. } \\
{[27]}\end{array}$} & \multirow{2}{*}{$\begin{array}{l}\text { constant } \\
\text { value } \\
\end{array}$} & \multirow{2}{*}{ varying of $\mathrm{T}$} & IGC & 104,197 & 0.0856 \\
\hline & & & USCG & - & - \\
\hline \multirow{2}{*}{$\begin{array}{l}\text { present study } \\
\text { (base tank case) }\end{array}$} & \multirow{2}{*}{ varying of $\mathrm{T}$} & \multirow{2}{*}{ varying of $\mathrm{T}$} & IGC & 110,271 & 0.0927 \\
\hline & & & USCG & 88,570 & 0.0745 \\
\hline
\end{tabular}

Table 13. BOR results of present study for 6 cases of KC-1 tanks with different blowing agent for IGC and USCG conditions

\begin{tabular}{|l|l|c|c|}
\hline \multirow{2}{*}{ blowing agent } & \multicolumn{1}{|c|}{$\begin{array}{c}\text { heat flow } \\
{[\mathbf{W}]}\end{array}$} & \multirow{2}{*}{ IGC } & \multirow{2}{*}{ USCG } \\
\cline { 2 - 3 } & $\begin{array}{r}\text { BOR } \\
{[\% / \text { day }]}\end{array}$ & & \\
\hline \multirow{2}{*}{ HFC-365mfc } & heat flow & 114,654 & 91,904 \\
\cline { 2 - 4 } & BOR & 0.0964 & 0.0773 \\
\hline \multirow{2}{*}{$\begin{array}{l}\text { HFC-245fa } \\
\text { (base tank case) }\end{array}$} & heat flow & 110,271 & 88,570 \\
\cline { 2 - 4 } & BOR & 0.0927 & 0.0745 \\
\hline \multirow{2}{*}{ HFC-245fa-e } & heat flow & 109,576 & 87,823 \\
\cline { 2 - 3 } & BOR & 0.0921 & 0.0738 \\
\hline
\end{tabular}

\section{CONCLUSION AND FUTURE WORK}

In this study, numerical thermal analysis is performed to calculate the BOR for KC-1 LNG tanks that has been recently developed by KOGAS. Unlike the double insulation structures of Mark-III and GT96, KC-1 insulation is composed of a single insulation structure comprised of high density rigid polyurethane foam (H-PUF) with a blowing agent in its cells. The new insulation structural design simplified the geometry of insulation structure facilitating construction and maintenance of the tank while meeting the insulation performance of a double insulation structured tank. The 6 tank cases are studied: 3 cases for IGC condition and 3 cases for USCG condition. In each of the 3 tank cases one of 3 HFC blowing agents is filled in H-PUH layer of insulation: 1,1,1,3,3-pentafluorobutane (HFC-365mfc), 1,1,1,3,3-pentafluoropropane (HFC-245fa) and HFC-245fa enhanced (HFC-245fa-e).
For the IGC condition, predicted BOR is $0.0927 \% /$ day for the base tank case in which the cells of H-PUF layer is blown with HFC-245fa. For the tank cases that used HFC-365mfc and HFC-245fa-e as a blowing agent, the calculated BOR are $0.0964 \% / d a y$ and $0.0921 \% / d a y$, respectively. In the USCG condition, the BOR calculated for the base tank case is $0.0745 \%$ /day, while BOR of $0.0773 \%$ /day and 0.0738 $\% /$ day are predicted for the cases that used HFC- $365 \mathrm{mfc}$ and HFC-245a-e as a blowing agent, respectively. The BOR results of all 6 tank cases for IGC and USCG conditions are shown to satisfy both the $0.15 \%$ / day regulation as proposed by IMO and the $0.12 \%$ /day limit set by KOGAS.

The results of temperature distribution of the $\mathrm{BC}$ (ballast compartment) for both the IGC and USCG conditions show that $\mathrm{BC}$ is designed with consideration of the structural support (ballast water space and hull shape), maintenance and safety response such as a measure to LNG leakage rather than to improve the insulation performance. A thermal analysis of the KC-1 insulation for IGC condition showed that the insulation performance within the H-PUF layer is $97.74 \%$ of the insulation, indicating the importance of this layer in the overall insulation performance of KC-1 LNG tank. The thermal conductivity and thickness of H-PUF are considered to be important factors in determining insulation performance in KC-1 LNG tank design. Therefore, incorporation of advanced insulation materials with an environmentally friendly refrigerant that has good physical properties may further improve the insulation performance which can meet the required insulation performance as well as the environmental regulations.

Further study requires careful consideration in three research areas. First, the study of stratification, boiling, and sloshing phenomenon that can occur within a LNG tank during the sea transportation of LNG carriers should be pursued further as these factors affect the amount of BOG generation. For example, during the actual sea transport of a LNG carrier, the structural disturbances such as ship's movement and wind speed, sea waves, and internal vibrations within the ship as well as the radiation heat transfer between the ship and space all attribute to the boiling two-phase phenomena within the tank. Second, it is necessary to obtain experimental BOR and thermal data to validate the numerically calculated results. Finally, it is necessary to study the aging of insulation layers such as the environmentally friendly H-PUF whether it can effectively sustain the insulation performance for extended time.

\section{ACKNOLEDGEMENT}

The present research was conducted by the research fund of Dankook University in 2014

\section{BIBLOGRAPHY}

1. International Gas Union (IGU), Ed.: 2016 Edition, World LNG Report. 2016. 
2. Shin, M.W., Shin, D.I., Choi, S.H., Yoon, E.S., Han, C.H.: Optimization of the operation of boil-off gas compressors at a liquefied natural gas gasification plant. Industrial \& Engineering Chemistry Research. Vol. 46, 2007, pp. 6540-6545.

3. Kurle, Y.M., Wang, S., Xu, Q.: Simulation study on boil-off gas minimization and recovery strategies at $L N G$ exporting terminals. Applied Energy. Vol. 156, 2015, pp. 628-641.

4. Koyama, K.: CFD simulation on LNG storage tank to improve safety and reduce cost, in Systems Modeling and Simulation, Anonymous Springer, 2007, pp. 39-43.

5. Hasan, M.F., Zheng, A.M., Karimi, I.: Minimizing boil-off losses in liquefied natural gas transportation. Industrial \& Engineering Chemistry Research. Vol. 48, 2009, pp. 9571-9580.

6. Dobrota, Đ, Lalić, B., Komar, I.: Problem of boil-off in LNG supply chain. Transactions on Maritime Science. Vol. 2, 2013, pp. 91-100.

7. Migliore, C., Tubilleja, C., Vesovic, V.: Weathering prediction model for stored liquefied natural gas (LNG). Journal of Natural Gas Science and Engineering. Vol. 26, 2015, pp. 570-580.

8. Martinez Romera, B.: The Paris agreement and the regulation of international bunker fuels. Review of European, Comparative \& International Environmental Law. Vol. 25, 2016, pp. 215-227.

9. Kanazawa, T., Kudo, K., Kuroda, A., Tsui, N.: Experimental study on heat and fluid flow in LNG tank heated from the bottom and the sidewalls. Heat Transfer-Asian Research. Vol. 33, 2004, pp. 417-430.

10. Kim, S.S., Choi, S.H.: A study on boil-off gas rate test of KC-1 closed mock-up tank. Proceedings of the 2010 the Korean Institute of Gas, 2010, pp. 29-35.

11. Han, M.S., Choi, S.J., Kim, J.M., Kim, Y.H., Kim, W.N., Lee, H.S., Sung, J.Y.: Effects of silicone surfactant on the cell size and thermal conductivity of rigid polyurethane foams by environmentally friendly blowing agents. Macromolecular Research. Vol. 17, 2009, pp. 44-50.

12. Lee, Y.B., Baek, K.H., Choe, K.H., Han, C.H.: Development of mass production type rigid polyurethane foam for $L N G$ carrier using ozone depletion free blowing agent. Cryogenics. Vol. 80, 2016, pp. 44-51.

13. I.G.C. Code, Ed.: International Code for the Construction and Equipment of Ships Carrying Liquefied Gases in Bulk. Chapter, 2003.
14. Lee, Y., Choe, K.: Development of polyurethane foam insulator with high thermal insulation performance for KC-1 LNG carrier. The Twenty-Fifth International Offshore and Polar Engineering Conference, 2015, .

15. Lee, B.J., Kim, S.B.: Current state of the polymer material technology for cryogenic. Prospectives of Industrial Chemistry. Vol. 17, 2014, pp. 1-11.

16. Jin, K.K., Oh, B.T., Kim, Y.K., Yoon, I.S., Yang, Y.C.: An assessment of structure safety for basic insulation panel of KC-1 LNG cargo containment system under sloshing load. Journal of the Korean Institute of Gas. Vol. 17, 2013, pp. 85-89.

17. Choi, S.W., Roh, J.U., Kim, M.S., Lee, W.I.: Analysis of two main LNG CCS (cargo containment system) insulation boxes for leakage safety using experimentally defined thermal properties. Applied Ocean Research. Vol. 37, 2012, pp. 72-89.

18. Marquardt, E., Le, J., Radebaugh, R.: Cryogenic material properties database, in Cryocoolers 11, Anonymous Springer, 2002, pp. 681-687.

19. Han, K.C., Hwang, S.W., Cho, J.R., Kim, J.S., Yoon, J.W., Lim, O., Lee, S.B.: A study on the boil-off rate prediction of LNG cargo containment filled with insulation powders. Journal of the Computational Structural Engineering Institute of Korea. Vol. 24, 2011, pp. 193-200.

20. Heo, J.U., Lee, Y.J., Cho, J.R., Ha, M.K., Lee, J.N.: Heat transfer analysis and BOG estimation of membrane-type LNG cargo during laden voyage. Transactions of the Korean Society of Mechanical Engineers A. Vol. 27, 2003, pp. 393-400.

21. Heo, J.H., Jeon, Y.H.: Temperature distribution for a membrane type LNGC cargo tank. Journal of the Society of Naval Architects of Korea. Vol. 34, 1997, pp. 108-118.

22. Heo, J.H.: Heat flux calculation for thermal equilibrium of cofferdam in a LNG carrier. Journal of the Society of Naval Architects of Korea. Vol. 35, 1998, pp. 98-106.

23. Song, S.O., Lee, J.H., Jun, H.P., Sung, B.Y., Kim, K.K., Kim, S.G.: A study on the three-dimensional steady state temperature distributions and BOR calculation program deveolpment for the membrane type LNG carrier. Journal of Korean Society of Marine Engineering. Vol. 23, 1999, pp. 140-149.

24. Lee, J.H., Kim, K.K., Ro, S.T., Chung, H.S., Kim, S.G.: A study on the thermal analysis of spray cooling for the membrane type LNGC during the cool-down period. Transactions of the Korean Society of Mechanical Engineers B. Vol. 27, 2003, pp. 125-134. 
25. Lee, J.H.: Thermal analysis comparison of IMO with USCG design condition for the INGC during the cool-down period. Transactions of the Korean Society of Mechanical Engineers B. Vol. 28, 2004, pp. 1390-1397.

26. Jang, E.K., Jung, Y.C.: Prediction method of the BOG for the membrane type LNGC in Middle East route. Journal of Korean Navigation and Port Research. Vol. 28, 2004, pp. 365-372.

27. Miana, M., Legorburo, R., Díez, D., Hwang, Y.H.: Calculation of boil-off rate of liquefied natural gas in mark III tanks of ship carriers by numerical analysis. Applied Thermal Engineering. Vol. 93, 2016, pp. 279-296.

28. Lambelet, M., van de Flierdt, T., Crocket, K., Rehkämper, M., Kreissig, K., Coles, B., Rijkenberg, M.J., Gerringa, L.J., de Baar, H.J., Steinfeldt, R.: Neodymium isotopic composition and concentration in the western north atlantic ocean: Results from the GEOTRACES GA02 section. Geochimica Et Cosmochimica Acta. Vol. 177, 2016, pp. 1-29.

29. Sharqawy, M.H., Lienhard, J.H., Zubair, S.M.: Thermophysical properties of seawater: A review of existing correlations and data. Desalination and Water Treatment. Vol. 16, 2010, pp. 354-380.

30. Zakaria, M.S., Osman, K., Saadun, M.N.A., Manaf, M.Z.A., Hanafi, M., Hafidzal, M.: Computational simulation of boil-off gas formation inside liquefied natural gas tank using evaporation model in ANSYS fluent. Applied Mechanics and Materials, 2013, pp. 839-844.

31. Rhee, S.H.: Unstructured grid based reynolds-averaged navier-stokes method for liquid tank sloshing. Journal of Fluids Engineering. Vol. 127, 2005, pp. 572-582.

32. Cable, M.: An evaluation of turbulence models for the numerical study of forced and natural convective flow in atria. 2009.

33. A. Hamon: One million cores: A breakthrough in CFD simulation. . Available: $<$ http://www.isgtw.org/feature/one$\underline{\text { million }}$-cores-breakthrough-cfd-simulation $>$ (accessed 27.05.15).

34. Shapiro, B.: Creating compact models of complex electronic systems: An overview and suggested use of existing model reduction and experimental system identification tools. IEEE Transactions on Components and Packaging Technologies. Vol. 26, 2003, pp. 165-172.

35. Roh, S.E., Son, G.H., Song, G.D., Bae, J.H.: Numerical study of transient natural convection in a pressurized LNG storage tank. Applied Thermal Engineering. Vol. 52, 2013, pp. 209-220.
36. Gaz Transport Report: Thermal calculation of $130 \mathrm{~K} \mathrm{~m}^{3}$ LNG carrier, 1991.

37. Chun, B.I.: A study on the 3-dimensional hull temperature distribution in LNG carriers, 1995.

\section{CONTACT WITH THE AUTHOR}

\author{
W.Jaewoo Shim \\ e-mail:wjshim@dankook.ac.kr \\ Department of Chemical Engineering \\ College of Engineering \\ Jukjeon-ro, 152 \\ Yongin-si, Gyeonggi-do \\ KOREA
}

